\title{
Effect of Hospitalization Anxiety on Recovery of in Patient in a Nigerian Teaching Hospital
}

\author{
${ }^{1}$ Medical Social Services Department, University College Hospital, Nigeria \\ ${ }^{2}$ Department of Social Work, University of Ibadan, Nigeria \\ ${ }^{3}$ Medical Social Services Department, University College Hospital, Nigeria \\ ${ }^{4}$ College of Health Sciences, Ladoke Akintola University of Technology, Nigeria
}

Oyinlola Oluwagbemiga*1, Ojedokun Isaiah Mobolaji² ${ }^{2}$ Mainoo Blessing ${ }^{3}$ and Oyinlola Oluwayinka Tiwalade ${ }^{4}$

Received Date: December 21, 2017; Published Date: January 19, 2018

*Corresponding author: Oyinlola Oluwagbemiga, University College Hospital, Nigeria; Email: gsticks2@gmail.com

\begin{abstract}
Hospitalization Anxiety of patient are characterized by physical symptoms which are partly caused by the brain which sends lots of messages down nerves to various parts of the body when you are anxious causing negative forms of recovery in patients. The study instigates the effect of hospitalization anxiety on recovery of in-patient at State Hospital, Adeoyo, and Ibadan. The study adopted descriptive research of an ex-post facto type. 222 respondents were purposively selected for the study. The instrument adopted was a questionnaire to measure the hospitalization anxiety in patient. Five research hypotheses were tested at 0.05 level of significance using multiple regression analysis and Analysis of Variance (ANOVA) was used to analyze the responses. The result of hypothesis one revealed that, there was a significant effect of Hospitalization anxiety on emotional recovery of patients in State Hospital in Ibadan (f-cal ${ }_{5,216}=78.171, p<0.05$ ), hypothesis two showed that, there was a significant effect of hospitalization anxiety on spiritual recovery of patients in State Hospital in Ibadan (f-cal ${ }_{5,216}=37.465 \mathrm{p}<0.05$ ), hypothesis three also revealed that, there is a significant effect of hospitalization anxiety on physical recovery of patients in State Hospital, Adeoyo, Ibadan ( $\mathrm{f}-\mathrm{cal}_{5,216}=91.252 \mathrm{p}<0.05$ ) while the fourth hypothesis showed that, there is a significant effect of hospitalization anxiety on social recovery of patients in State Hospital, Adeoyo, Ibadan (f-cal $\left.{ }_{5,216}=86.207, \mathrm{p}<0.05\right)$.

The fifth hypothesis revealed that, In terms of most significant effect social recovery contributed in State hospital hospitals in Ibadan ( $(=$ $-0.469 ; t=-0.21 .682 ; p<0.05)$. Next in terms of magnitude of contribution is Physical Recovery $(\beta=0.407 t=27.247 ; p<0.05)$. Next is, Spiritual Recovery $(B=0.257 t=5.284 ; p<0.05)$, then, emotional recovery $(B=0.175, t=12.821 ; p<0.05)$. Hence, the positive hospitalization anxiety had significant contribution to the recovery of patients presented at State Hospital, Ibadan. The number of patients being admitted to the hospital emphasizes the importance of patient centered care. Since patients are the future of a good hospital, it is important to foster a background that is rich in culture, education and art to enhance such a generation. This study therefore recommends that better social support in the hospital is needed to address hospitalization anxiety in patients to improved positive recovery from illness and diseases.
\end{abstract}

Abbreviations: ANOVA: Analysis of Variance; PD: Panic Disorder; GAD: Generalized Anxiety Disorder; SAD: Social Anxiety Disorder; PTSD: Posttraumatic Stress Disorder; OCD: Obsessive Compulsive Disorder; HARQ: Hospitalization Anxiety and Recovery Questionnaire; SA: Strongly Agreed; A: Agreed; SD: Strongly Disagreed; D: Disagreed

\section{Introduction}

Hospitalization is not defined by a specific amount of time, but by the moment an individual identifies their isolated situation. Anxiety of patient are characterized by physical symptoms which are partly caused by the brain which sends lots of messages down nerves to various parts of the body when you are anxious [1]. The nerve messages tend to make the heart, lungs, and other parts of the body work faster. In addition, patients release stress hormones, such as adrenaline (epinephrine), into the bloodstream when they are anxious [2]. These can also act on the heart, muscles and other parts of the body to cause symptoms. Anxiety is normal in stressful situations and can even be helpful. For example, most people will be anxious when threatened by an aggressive person, or before an important race. The burst of adrenaline (epinephrine) and nerve impulses which patient have in response to stressful situations can encourage a 'fight or flight' response [2].

Emotional recovery can be described as the mental health of an individual that is judged by self-reported or care-taker reported happiness, physical activity, amount of positivity, and visible energy [3]. Hospitalization of patient in the way that there 
is not a set time frame for patients presented in the hospital. I do not define the term child by a numerical age range; instead, my definition is based on the "social age" of an individual-a developmentally determined age that classifies an individual as a child. The explanation of the social age that patient intend to use to conduct research can be described as an individual that is still in the process of determining their self-identity while also being emotionally and physically dependent on family and loved ones.

Geist [3] states that "chronic disease affects an estimated $10-20 \%$ of all patients during childhood and adolescence." Luckily, advances in medicine in recent years, have increased the likelihood of surviving childhood illness and decreased the mortality rate. However, as survivors of illness during childhood, these individuals not only have to deal with "normal developmental stressors" but they are also attempting to manage the impact that long-term hospitalization can have which can possibly result in long lasting, detrimental effects Boyd, Hunsberger [4]. Exploring coping methods for hospitalization is essential for patients to properly adjust to an extended hospital stay. Patients handle these stressors in and out of the hospital by keeping busy with hobbies and activities, and exercise. If possible, while in the hospital it is helpful for patients to draw similarities to life at home, and distract themselves by using personal comforts to temporarily mask their illness [5].

Similarly [4] found that social support and physical support from family and friends has helped hospitalized patients cope with illness. Finding peers to relate to and a setting that allows for proper expression of the emotions felt after and during the diagnosis and treatment of an illness or a disorder is beneficial in dealing with the stressors of illness. Secondly, patients in the hospital tend to respond better to their circumstances when they are given or seek information about their condition they've been diagnosed with and the treatment process involved. If there is an increase in awareness about their situation they are more likely to feel more comfortable about their position [5]. Anxiety disorders during hospitalization are group of mental disorders characterized by feelings of anxiety and fear [6]. Anxiety is a worry about future events and fear is a reaction to current events. These feelings may cause physical symptoms, such as a fast heart rate and shakiness. There are a number of anxiety disorders: including generalized anxiety disorder, specific phobia, social anxiety disorder, separation anxiety disorder, agoraphobia, and panic disorder. The disorder differs by what results in the symptoms. People often have more than one anxiety disorder [7].

The cause of anxiety disorders is a combination of genetic and environmental factors. Risk factors include a history of child abuse, a family history of mental disorders, and poverty. They often occur with other mental disorders, particularly major depressive disorder, personality disorder, and substance use disorder [8]. To be diagnosed symptoms typically need to be present at least six months, be more than would be expected for the situation, and decrease functioning [8]. Other psychiatric and medical problems that may result in similar symptoms including hyperthyroidism, heart disease, caffeine, alcohol or cannabis use, and withdrawal from certain drugs [8]. Without treatments anxiety disorders tend to remain. Treatment may include lifestyle changes, counseling, and medications. Counseling is typically with a type of cognitive behavioral therapy [8]. Medications, such as antidepressants or beta blockers, may improve symptoms [2].

Studies suggest that the poor quality of care for anxiety in primary care may be related to difficulty recognizing and diagnosing anxiety disorders the increased time and enhanced skill needed to optimally engage such patients in care and a low perceived need for psychiatric treatment among patients [9]. However, an even greater barrier to the effective delivery of evidence-based care for anxiety is the non-unitary nature of anxiety disorders: instead of having one depressive disorder (major depression) to diagnose and treat, primary care physicians are faced with multiple anxiety disorders (eg, panic disorder [PD], generalized anxiety disorder [GAD], social anxiety disorder [SAD], and posttraumatic stress disorder [PTSD]). This multiplicity of disorders makes it hard to have any unitary traction for public health education efforts; physicians must remember different diagnostic and treatment approaches and, with the multitude of other problems they manage, this array of diagnostic algorithms and treatment options can become quite daunting [9].

Some anxiety disorders have also been found to be more prevalent among in patients than among non-admitted patients. In a review of 18 studies with a total of 4076 participants (2584 diabetic patients, 1492 control participants), Grigsby et al. [10] examined the prevalence of anxiety disorders and anxiety symptoms in chronic disease patients. The review found that $14 \%$ of chronic disease patients had any current anxiety disorder (as defined by either point prevalence in most studies or in the past 2-, 6- or 12-month intervals preceding the study in 4 studies) and identified the following additional current prevalence rates: Anxiety Disorder Not Otherwise Specified = 26.5\%, Simple Phobia $=21.6 \%$, Generalized Anxiety Disorder $(\mathrm{GAD})=13.5 \%$, Social Phobia $=7.3 \%$, Agoraphobia $=4.6 \%$, Panic $=1.3 \%$, Obsessive Compulsive Disorder (OCD) $=1.3 \%$ and Post-Traumatic Stress Disorder (PTSD) $=1.2 \%$. The presence of depression and anxiety among in-patients is associated with multiple behaviors that have a negative impact on disease management. These include increased smoking, alcohol or other drug abuse; poorer eating and appetite deregulation; and poorer self-managed metabolic control [11]. These behaviors, in turn, are associated with poorer health outcomes and greater disease related complications [11]. A recent meta-analysis of the impact of anxiety on diabetes complications found a moderate overall effect size across 27 studies. The review found that depression was significantly associated with nephropathy, neuropathy, macro vascular complications and sexual dysfunction [12]. 
Thus the identification and treatment of clinically significant anxiety and depression should be a priority in the treatment of disease. Against this background the study examines the effect of hospitalization anxiety on recovery of in-patient in a Nigerian Teaching Hospital.

\section{Problem Statement}

Patients differ in their recovery from, and their response to treatment while on admission. Such variability is also apparent within comparable treatment procedures. The cause of differences in recovery of patients with anxiety disorder during hospitalization and thus has led to suggestions that psychological factors such as anxiety, may be associated with recovery. The existence and identification of such association has obvious clinical importance. Anxious patients are faced with different challenges during hospitalization like depression, mood disorder and low self-esteem; however there are inadequate personnel to provide pre-admission counseling to address the hospitalization anxiety in patient. Most hospitals, does not have adequate support services for in-patients to improve recovery e.g. the use of muscle relaxation technique. Age was discovered to be a risk factor to hospitalization anxiety in the recovery of patients as there are tendencies for poor ability to cope with the hospitalization procedures. Another significant problems in hospitalization anxiety are direct verbalization, value connections, threats to self, death experiences, diversion or social discourse, coping and unresolved relationship issues, etc however, there is a complexity of poor anxiety outcomes.

The clinical importance of anxiety related to hospitalization and recovery is poorly evident through the negative effect it exerts on the recovery of in-patients. The uncertainty is apparent regarding the influence of trait and pre-treatment state anxiety and post treatment pain. Hospitalization anxiety is still a serious problem for patient in the hospital as very few studies have been conducted to obtain the patient's perspectives on the experience of anxiety and the events and situations that aggravate and ameliorate it. Since anxiety is a subjective experience and health care professionals have been shown to inaccurately perceive and understand such anxiety in patients with hospitalization problem there is need for adequate psychosocial support for improved recovery. Therefore, the study investigates the effect of hospitalization anxiety on recovery of in-patient in a Nigerian Teaching Hospital.

\section{Objective of the Study}

The general objective of the study is to examine the effect of hospitalization anxiety on recovery of in-patient in a Nigerian Teaching Hospital

Specific objective of the study is to:

a) Examine the effect of hospitalization anxiety on emotional recovery of patients in a Nigerian Teaching Hospital b) Investigate the effect of hospitalization anxiety on spiritual recovery of patients in a Nigerian Teaching Hospital

c) Find out the effect of hospitalization anxiety on physical recovery of patients in a Nigerian Teaching Hospital

d) Examine the effect of hospitalization anxiety on social recovery of patients in a Nigerian Teaching Hospital

e) To investigate the joint and relative effect of hospitalization anxiety on the recovery of patients in a Nigerian Teaching Hospital.

\section{Research Hypotheses}

a) Hypothesis One: There is no significant effect of hospitalization anxiety on emotional recovery of patients in a Nigerian Teaching Hospital

b) Hypothesis Two: There is no significant effect of hospitalization anxiety on spiritual recovery of patients in a Nigerian Teaching Hospital

c) Hypothesis Three: There is no significant effect of hospitalization anxiety on physical recovery of patients in a Nigerian Teaching Hospital

d) Hypothesis Four: There is no significant effect of hospitalization anxiety on social recovery of patients in a Nigerian Teaching Hospital

e) Hypothesis Five: There is no relative effect of hospitalization anxiety on the recovery of patients in a Nigerian Teaching Hospital.

\section{Implication of Hospitalization Anxiety Disorder to Medical Social Work Practice}

Social workers play a prominent role within mental health clinics and outpatient facilities. Mental health clinics can be supported by both private and public funding. Mental health services provided in these settings can vary greatly in terms of intensity and duration. Social workers working within a mental health setting can provide case management services and direct mental health services. Frequently, social workers in mental health clinics work as part of a team [13]. The problems addressed by social workers in mental health clinics and outpatient facilities include those associated with the stress of everyday living; behavioral deficiencies; crises brought on by emotional, environmental, or situational occurrences; eating disorders; parent child problems; marital problems; depression; schizophrenia; bipolar disorders; and other forms of psychopathology [13].

\section{Overview of Functions}

The Gibelman [13] observed that, social workers employed with mental health clinics can have a range of job functions depending on their specific roles. Possible job titles include, but are not limited to, clinical social worker, licensed clinical social 
worker, mental health specialist, clinician, therapist, counselor, and director or case manager. Job functions that a social worker might perform within a mental health clinic include:

a) Determining client eligibility for services

b) Conducting bio-psychosocial assessments and social histories

c) Assessing clients for substance use, support systems, physical and emotional functioning, financial stability, safety, suicidal/ homicidal ideation, etc.

d) Developing and implementing treatment plans and discharge plans that adhere with client self-determination

e) Providing direct therapeutic services such as individual, family or group therapy regarding a specific mental health issue

f) Providing crisis management including assessment for safety

g) Advocating for client services

h) Providing case management services including, but not limited to, referrals to community resources, collaboration with other professionals, etc.

i) Promoting mental health services provided by the clinic to the greater community

j) Participating in grant writing and evaluation to garner or maintain program funding

k) Identifying and resolving ethical issues

l) Managing, training and supervising staff and

m) Functioning as part of a multidisciplinary treatment team.

Social workers employed with mental health clinics play a vital role in addressing and treating mental health issues. Through the roles social workers assume, they have the opportunity to collaborate in the improvement of the lives of the people they serve. Social workers who provide mental health services are required to be licensed by the state in which they practice. Social workers providing therapy are also required to have a master's degree. Their roles can vary from client to client, providing a variety of experiences on a daily basis. However, like social workers in other settings, the caseloads of social workers in a mental health clinic or outpatient facility may be high. Clinics and agencies often face resource constraints, such as limited space, as well as insufficient funding for supplies or additional training. Social workers in these settings may also experience secondary trauma or emotional stress from helping their clients manage intense circumstances.

\section{Methodology}

\section{Research Design}

The research design adopted for the study is descriptive survey research design. Such a design does not involve the manipulation of variables in the study. However, this particular study was designed to survey effect hospitalization anxiety on recovery of patients in selected government hospitals in Ibadan metropolis.

\section{Population}

The target population for this study is patients presented for admission at the Adeoyo Maternity Teaching Hospital and Chest Hospital, Ring-Road, Ibadan

\section{Sample and Sampling Technique}

The study purposively sampled 225 patients in selected government hospitals in selected in Ibadan Metropolis. The study will purposively selected 225 patients on admission at Adeoyo Maternity Teaching Hospital and Chest Hospital, RingRoad, Ibadan

\section{Research Instrument}

The research instrument for the study was a single questionnaire tagged: Hospitalization Anxiety and Recovery Questionnaire (HARQ). The questionnaire was designed on a fourpoint rating scale of Strongly Agreed (SA), Agreed (A), Strongly Disagreed (SD) and Disagreed (D), with the corresponding values of $4,3,2,1$. The structured questionnaire was made up of two sections viz A and B. Section A consists of item questions on demographic characteristics (age, gender, sex, religion, monthly income, and occupation) of patients on admission at the selected government hospitals. Section B consists of items measuring the Anxiety among couples in Ibadan metropolis. The item was drawn from Westside Test Anxiety Scale developed by Richard [14]. The scale was adapted to measure the Anxiety among couples in Ibadan metropolis. The participants will be asked to respond to a 4-point rating scale ranging from strongly Agree (SA) to strongly disagree (SA). Recovery Scale was adapted from Sethi, Seligman titled 'Recovery Stages in Patient Questionnaire. This will contain of information or statements on emotional, social, spiritual recovery and physical recovery. The respondents were asked to respond to a 3 point scale ranging from Yes (1), No (2) and I don't Know (3).

\section{Administration of the Instrument}

The researcher obtained a letter of introduction from her Supervisor who wrote a letter of introduction to introduce the researcher as a postgraduate student of the Department of Social Work. The researcher submitted the letter to all the selected government hospitals in Ibadan and ethical approval was obtained from the State Ministry of Health, Oyo State before the commencement of data collection. The researcher instructed the participants about the content of the instrument and how to fill it. The researchers spent about 30 minutes with each respondent. The results obtained from this study were coded for analysis.

\section{Data Analysis}

The responses gathered from the respondents were analyzed using descriptive statistics of simple percentages and frequency 


\section{Psychology and Behavioral Science International Journal}

count for the demographic characteristics while Analysis of Variance was used to test the effect on the variables. A hypothesis generated was tested at 0.05 level of significance (Table 1 ). The results presented above showed that, $48.6 \%$ of the respondents are male while $51.4 \%$ of the respondents are female. The result indicated that, more than half of the respondents are female. $77.5 \%$ of the respondents are Christian, $14 \%$ practice Islamic religion, while $8.6 \%$ practice the traditional religion. More than half of the respondents are Christians. $36.9 \%$ of the respondents are between ages of $15-20 y e a r s, 39.6 \%$ of the respondents are between the ages of 21-25years while $23.4 \%$ of the respondents

Table 1: Frequency distribution of respondents by Gender.

\begin{tabular}{|c|c|c|}
\hline Variables & Frequency & Percentage \\
\hline Male & 108 & 48.6 \\
\hline Female & 114 & 51.4 \\
\hline \multicolumn{3}{|l|}{ Religion } \\
\hline Christianity & 172 & 77.5 \\
\hline Islam & 31 & 14.0 \\
\hline Traditional & 19 & 8.6 \\
\hline \multicolumn{3}{|l|}{ Age } \\
\hline 15-20years & 82 & 36.9 \\
\hline 21-25years & 88 & 39.6 \\
\hline 26-30years & 52 & 23.4 \\
\hline \multicolumn{3}{|l|}{ Marital Status } \\
\hline Never married & 38 & 17.1 \\
\hline Married & 169 & 76.1 \\
\hline Separated & 15 & 6.8 \\
\hline \multicolumn{3}{|l|}{ Ethnicity } \\
\hline Yoruba & 207 & 93.2 \\
\hline Igbo & 15 & 6.8 \\
\hline \multicolumn{3}{|l|}{ Educational Level } \\
\hline No formal education & 15 & 6.8 \\
\hline Primary Education & 93 & 41.9 \\
\hline Secondary education & 73 & 32.9 \\
\hline Tertiary education & 41 & 18.5 \\
\hline
\end{tabular}

\section{Testing of Research Hypotheses}

Hypothesis One: There is no significant effect of hospitalization anxiety on emotional recovery of patients in State Hospital, Adeoyo, and Ibadan. Based on the results presented in (Table 2) which showed that, there was a significant effect of Hospitalization anxiety on emotional recovery of patients

Table 2: ANOVA showing the effect of hospitalization anxiety on emotional recovery of patients in State Hospital, Ibadan.

\begin{tabular}{|c|c|c|c|c|c|}
\hline & Sum of Squares & Df & Mean Square & F & Sig. \\
\hline Between Groups & 1000.955 & 5 & 200.191 & 78.171 & \\
\hline Within Groups & 12.671 & 216 & 3.188 & & \\
\hline Total & 1013.626 & 221 & & & \\
\hline
\end{tabular}

are between the ages of 26-30years. However, majority of the respondents are between the ages of 21-25years. About 17.1\% are never married, $76.1 \%$ are married while $6.8 \%$ separated. More than half of the respondents are married. $93.2 \%$ of the respondents are from the Yoruba tribe while $6.8 \%$ are from the Igbo tribe while there was no representation from other ethno-religious group. $6.8 \%$ of the respondents had no formal education, $41.9 \%$ of the respondents had primary education, 32. $9 \%$ had secondary school education while $18.5 \%$ of the respondent had only tertiary school education. in State Hospital in Ibadan. The results showed that, f-ratio is greater than the f-table ( $\mathrm{f}-\mathrm{cal}_{5,216}=78.171, \mathrm{p}<0.05$ ). The results reject the null hypothesis and accept the alternate hypothesis which states that, there is a significant effect of hospitalization anxiety on emotional recovery of patients in State Hospital in Ibadan. 
Hypothesis Two: There is no significant effect of hospitalization anxiety on spiritual recovery of patients in State Hospital, Adeoyo, and Ibadan. The results presented in (Table 3) revealed that, there was a significant effect of hospitalization anxiety on spiritual recovery of patients in State Hospital in
Ibadan. The results showed that, f-ratio is greater than the f-table ( $f-\mathrm{cal}_{5,216}=37.465 \mathrm{p}<0.05$ ). The results rejected the null hypothesis and accept the alternate hypothesis which states that, there is a significant effect of hospitalization anxiety on spiritual recovery of patients in State Hospital in Ibadan.

Table 3: ANOVA showing the effect of hospitalization anxiety on spiritual recovery of patients in State Hospital in Ibadan.

\begin{tabular}{|c|c|c|c|c|c|}
\hline & Sum of Squares & df & Mean Square & F & Sig. \\
\hline Between Groups & 1379.649 & 5 & 275.930 & 37.465 & .000 \\
\hline Within Groups & 193.846 & 216 & 1.897 & & \\
\hline Total & 1573.495 & 221 & & & \\
\hline
\end{tabular}

Hypothesis Three: There is no significant effect of hospitalization anxiety on physical recovery of patients in State Hospital, Adeoyo, and Ibadan. Based on the results presented in (Table 4) presented above it showed that, there is a significant effect of hospitalization anxiety on physical recovery of patients in State Hospital, Adeoyo, and Ibadan. Since the f-ratio is greater than the f-table (f-cal ${ }_{5,216}=91.252 \mathrm{p}<0.05$ ). The results rejected the null hypothesis while the alternate hypothesis was accepted which states that, there is a significant effect of hospitalization anxiety on physical recovery of patients in State Hospital,

Adeoyo, Ibadan.

Table 4: ANOVA showing the effect of hospitalization anxiety on physical recovery of patients in State Hospital, Adeoyo and Ibadan.

\begin{tabular}{|c|c|c|c|c|c|}
\hline & Sum of Squares & df & Mean Square & F & Sig. \\
\hline Between Groups & 663.698 & 5 & 132.740 & 91.252 & .000 \\
\hline Within Groups & 75.541 & 216 & 6.913 & & \\
\hline Total & 739.239 & 221 & & & \\
\hline
\end{tabular}

Hypothesis Four: There is no significant effect of hospitalization anxiety on social recovery of patients in State Hospital, Adeoyo, and Ibadan.

ANOVA showing the effect of hospitalization anxiety on social recovery of patients in State Hospital, Adeoyo, and Ibadan. From the on the results presented in (Table 5) presented above it showed that, there is a significant effect of hospitalization

Table 5: ANOVA showing the effect of hospitalization anxiety on social recovery of patients in State Hospital, Adeoyo, Ibadan.

\begin{tabular}{|c|c|c|c|c|c|}
\hline & Sum of Squares & $\mathrm{df}$ & Mean Square & F & Sig. \\
\hline Between Groups & 2564.656 & 5 & 512.931 & 86.207 & .000 \\
\hline Within Groups & 48.462 & 216 & .224 & & \\
\hline Total & 2613.117 & 221 & & & \\
\hline
\end{tabular}

Hypothesis Five: There is no joint and relative effect of hospitalization anxiety on the recovery of patients in State Hospital, Adeoyo, and Ibadan. The table presented above in (Table 6a) showed the combination of the independent variables (hospitalization anxiety) account for $99 \%$ of the variance in health and performance variables (R2 adjusted $=0.988$ ). The analysis of variance of the multiple regression data yielded an F-ratio value which was found to be significant at 0.05 alpha level $\left(\mathrm{F}_{4,217}=45.402 ; \mathrm{p}<0.05\right)$. However, results obtained in (Table $6 \mathrm{~b}$ ) above indicate the effect of each of the independent anxiety on social recovery of patients in State Hospital, Adeoyo, Ibadan. The results showed that, $\mathrm{f}$-ratio is greater than the f-table (f-cal ${ }_{5,216}=86.207, \mathrm{p}<0.05$ ). The results did not give support to the null hypothesis while the alternate hypothesis was accepted which states that, there is a significant effect of hospitalization anxiety on social recovery of patients in State Hospital, Adeoyo, Ibadan. variables (hospitalization anxiety variables) on the dependent variable (recovery). In terms of most significant effect social recovery contributed in State hospital hospitals in Ibadan $(B=$ $-0.469 ; \mathrm{t}=-0.21 .682 ; \mathrm{p}<0.05)$. Next in terms of magnitude of contribution is Physical Recovery $(~(\beta=0.407 t=27.247$; $p<0.05)$. Next is, Spiritual Recovery $(~ \beta=0.257 t=5.284 ; p<0.05)$, then, emotional recovery $(~ \beta=0.175, t=12.821 ; p<0.05$ ). Hence, the positive hospitalization anxiety had significant contribution to the recovery of patients presented at State Hospital, Ibadan. 
Table 6a: Multiple regression analysis showing the joint contribution of hospitalization anxiety on recovery of patients in State Hospital, Adeoyo, Ibadan.

\begin{tabular}{|c|c|c|c|c|}
\hline \multicolumn{5}{|c|}{$R=0.994$} \\
\hline \multicolumn{5}{|c|}{$\mathrm{R}^{2}=\mathbf{0 . 9 8 8}$} \\
\hline \multicolumn{5}{|c|}{ Adjusted $R^{2}=0.618$} \\
\hline \multicolumn{5}{|c|}{ Standard error of estimate $=\mathbf{1 . 3 8 5 9 7}$} \\
\hline \multicolumn{5}{|c|}{ Analysis of Variance } \\
\hline & Sum of square & df & Mean square & $\mathbf{F}$ \\
\hline Regression & 2768.128 & 4 & 692.032 & \multirow{3}{*}{45.402} \\
\hline Residual & 32.327 & 217 & .149 & \\
\hline Total & 2800.455 & 221 & & \\
\hline
\end{tabular}

Table 6b: showing the contribution of independent variables (hospitalization anxiety) on the dependent variable.

\begin{tabular}{|c|c|c|c|c|c|}
\hline & \multicolumn{2}{|c|}{ Unstandardized Coefficients } & $\begin{array}{c}\text { Standardized } \\
\text { Coefficients }\end{array}$ & t & Sig. \\
\hline & B & Std. Error & Beta & & \\
\hline (Constant) & 1.061 & .277 & & 3.837 & .000 \\
\hline Spiritual. Recovery & .175 & .014 & .257 & 5.284 & .000 \\
\hline Emotional. Recovery & .293 & .023 & .175 & 12.821 & .000 \\
\hline Social. Recovery & .486 & .022 & .469 & 21.682 & .000 \\
\hline Physical. Recovery & .837 & .031 & .407 & 27.247 & .000 \\
\hline
\end{tabular}

\section{Discussion of Findings}

Ho1: The result of hypothesis one revealed that, there is a significant effect of hospitalization anxiety on emotional recovery of patients in State Hospital, Adeoyo, Ibadan, the result supported the findings of Holden, Gitelson [15] hospitalization anxiety increased prevalence of psychiatric symptoms, especially anxiety and psychosis in mentally retarded persons. Association between anxiety and self-injurious behavior was found. Furthermore, Hermanns [16] found that, self-report symptoms of depression and anxiety generally have found that most overlapping symptoms of depression and patients appear more strongly related to mood than to objective measures of disease. One symptom appears to be less related to mood, however, namely weight loss. The data suggest that weight loss is unrelated to either depression/anxiety or diabetes. The same study found that, obtained contrary results in their experimental study of hypoglycemia. This study suggests that hypoglycemia may directly lead to feelings of tension, irritability and low energy/fatigue. In the same vein, Mineka [17] found that, the integrative hierarchical model that incorporates elements from the tripartite model as well as from Barlow's hierarchical model. The integrative hierarchical model proposes that different disorders characterized by negative affect have both common and unique components. Similarly, Fagin [18] Providing an initial orientation of all services to patients and families is the first step in reducing patients" and family members" fear and anxiety and offering them a feeling of security and acceptance [19].

Ho2: There is no significant effect of hospitalization anxiety on spiritual recovery of patients in State Hospital, Adeoyo, and
Ibadan the result is supported with the findings of Mainoo, Oyinlola [20] found that, helping patients through spiritual care aids them to develop or restore hope for fuller recovery. Providers can convey to patients an understanding of the context of the illness, (e.g. that this is but one aspect of their lives). Helping patients find meaning in their lives and opportunities and supports to achieve successful experiences is an example of hope instillation.

Providers need hope, as well, particularly given that the inpatient provider's perspective is colored with experiences of people returning to hospital and of acute illness. Meeting with former patients who have moved forward in their recovery in the community is a strategy to help providers become more hopeful and believe in recovery. The strategy of connecting people who have moved on in recovery to the in-patient can be a powerful strategy to enable hope and a sense of possibility. [20] Found that, spiritual care is imperative for providers of mental health services should know and apply strategies to help patients empower themselves. This can happen both at the level of individual care, but also on the program level. The result is also in line with Attafua, Boocock [21] who found that, there is a significant effect of hospitalization anxiety on spiritual recovery of patients. This could be achieved through peersupport services in in-patient settings can be an effective way to promote recovery. Peer-provided services are delivered by peer support workers who are receiving or have received mental health services for psychiatric illness.

Ho3: There was a significant effect of hospitalization anxiety on physical recovery of patients in State Hospital, Adeoyo, 
Ibadan, the result is in tandem with the findings of Furthermore, Ofidna found that, physical recovery could be achieved through hospital anxiety from family members and other significant social network improves adherence to medication and increased access to treatment of tuberculosis patients attending a primary health centre. In the same vein, Adepoju [22] revealed that, hospitalized anxiety in patients tends not to recover fully when their physical burden of attached to management is becoming worrisome and there is inadequate support from family members.

Ho4: There was a significant effect of hospitalization anxiety on social recovery of patients in State Hospital, Adeoyo, Ibadan, the result supports the findings of Animashau [23] that, companionship from families, friends, and healthcare providers contributed to the patients' support system in different ways, but must be expressed by patients themselves. However, Patientprovider interactions were described as overwhelmingly positive, which likely contributed to improved patient psychosocial wellbeing. Perceived stigma in the community, lack of psychosocial support, and forced lifestyle changes associated with illness contribute to the significant mental health needs of this patient population. Furthermore, Sagbakken [24] found that, social recovery from hospital anxiety help patients cope with anxiety, depression, and frustration is important to enhance fuller recovery. Also, Olusanya [25] that, social recovery from hospital anxiety from other social networks of patients helps to achieve treatment adherence and the quantification of stigma among the patients and the society at large. Furthermore, Ogah [26] observed that, communities, families, patients and health providers are the major sources of companionship for patients in a resource constrain environment, this will restore confidence in patients in achieving personal goals. In the same vein, Adelakun [27] observed that, companionship support from friends, family members and significant others have reduced the number of cases of patients that discharge against medical advice.

\section{References}

1. American Psychiatric Association (2013) Diagnostic and statistical manual of mental disorders $\left(5^{\text {th }}\right.$ edn.). American Psychiatric Publishing, Arlington, USA.

2. World Health Organisation (2013) International Statistical Classification of Diseases and Related Health Problems, Tenth Revision. Geneva, Switzerland.

3. Geist R (2003) Psychosocial issues in the patient with chronic conditions. Best Practice \& Research Clinical Gastroenterology 17(2): 141152

4. Boyd JR, Hunsberger M (2008) Chronically ill patients coping with repeated hospitalizations: their perceptions and suggested interventions. Journal of Pediatric Nursing 13(6): 330-342.

5. Mc Caffrey (2006) Major stressors and their effects on the well-being of children with cancer. Journal of Pediatric Nursing Feb 21(1): 59-66.
6. Peter A (2012) So, what does 'The Scream’ mean?. Financial Times.

7. DSM (2013) Diagnostic Statistical Manual of Mental Disorders, $\left(5^{\text {th }}\right.$ Edn) Edited by American Psychiatric Association.

8. Craske MG (2016) Anxiety. Lancet, London.

9. Mojtabai R (2002) Medication costs adherence and health outcomes among Medicare beneficiaries. Health Aff (Millwood) (22): 220-229.

10. Grigsby AB, Anderson RJ, Freedland KE, Clouse RE, Lustman PJ (2002) Prevalence of anxiety in adults with diabetes: a systematic review. J Consult Clin Psychol.

11. Gonder Frederick LA (2002) Diabetes and behavioral medicine: the second decade. Journal of Consult Clinical Psychology 70(3): 611-625.

12. De Groot M, Anderson R, Freedland KE, Clouse RE, Lustman PJ (2001) Association of depression and diabetes complications A meta analysis. Psychosomatic Medicine (63): 619-630.

13. Gibelman M (2005) Encyclopedia of Social Work, Oxford Press.

14. Richard JL (2006) Prospective nationwide surveillance of hospitalizations due to pertussis in children 2006-2010 Pediatrics Infection Diseases Journal 33(2): 147-151.

15. Holden ZA, Gitelson AA (2003) Treating young veterans: Promoting resilience through Social Services. Journal of Military Social Work UK.

16. Hermanns E (2003) Biochemical and pharmacological control of the multiplicity of coupling at G-protein coupled receptors. Pharmacol Ther 99(1): 25-44.

17. Mineka HL (2008) The Hospital Anxiety and Depression Scale journal of psychosomatic research 2008 (65): 115-121.

18. Fagin C (2007) Nurse Practice Environments and Outcomes: Implications for Oncology Nursing. Oncology Nursing Forum 32(4): 765-772.

19. Blessing M, Oluwagbemiga O (2017) Effectiveness of Social Support in Coping with Stroke by Medically Ill Patient in Ibadan. Int J Neurorehabilitation 4: 281.

20. Mojoyinola JK, Ojedokun MI (2014) Impact of Emotional Reactions on Patients Recovery from Physical Illness: Implications for the Medical Social Workers. Ethno Medicine 4(2): 139-144.

21. Attafua YO, Boocock U, Jamieson Craig IW (2004) Patterns of attachment A psychological study of the strange situation. London Lawrence Erlbaum.

22. Adepoju OE (2011) Effects of diabetes self-management programs on time to hospitalization among patients with type 2 diabetes A survival analysis model. Patient Education Counselling 95(1): 111-117.

23. Animashaun A (2001) Aetiology of cerebral palsy in African children. Afr J Med Sci 1971(2):165-171.

24. Sagbakken HJ (2011) Psychology $2^{\text {nd }}$ Edn. New York, USA.

25. Olusanya BO (2013) Factors associated with auditory neuropathy dys synchrony in a developing country. Audiology Medicine (6): 120-128.

26. Ogah (2012) Association between electrocardiographic left ventricular hypertrophy with strain pattern and left ventricular structure and function. Cardiology 2006(106): 14-21.

27. Adelekun TA (2009) Hypertension induced chronic renal failure clinical features management and prognosis. West Afr J Med 1998(17): 104-108. 
This work is licensed under Creative Commons Attribution 4.0 License

DOI:_10.19080/PBSIJ.2018.08.555734

\section{Your next submission with Juniper Publishers}

will reach you the below assets

- Quality Editorial service

- Swift Peer Review

- Reprints availability

- E-prints Service

- Manuscript Podcast for convenient understanding

- Global attainment for your research

- Manuscript accessibility in different formats

( Pdf, E-pub, Full Text, Audio)

- Unceasing customer service

Track the below URL for one-step submission https://juniperpublishers.com/online-submission.php 